Síntese - Rev. de Filosofia

v. 38 N. 122 (2011): 365-380

\title{
EXPERIÊNCIA RELIGIOSA E LINGUAGEM. CONSIDERAÇÕES HERMENÊUTICAS
}

(Religious experience and language: hermeneutical remarks)

\author{
Frederico Pieper ${ }^{*}$
}

Resumo: Este artigo aborda a categoria experiência religiosa tomando como referencial teórico o pensamento hermenêutico de $M$. Heidegger, especialmente suas considerações sobre a linguagem. Neste sentido, ao invés do abandono do uso desta categoria, propõe-se que compreenda a experiência religiosa para além da interpretação centrada no sujeito, indicando sua inserção num mundo.

Palavras-chave: Experiência religiosa, hermenêutica, linguagem, Heidegger.

Abstract: This article discusses the category of Religious experience, taking as theoretical reference Martin Heidegger's hermeneutical thought, mainly his remarks on language. Thus, instead of abandoning the use of this category, it is proposed to understand religious experience beyond the subjective interpretation and as inserted in the world.

Keywords: Religious experience, hermeneutics, language, Heidegger.

\footnotetext{
* Graduado em Teologia (EST-ICSP), História (USP) e Filosofia (USP). Mestre e doutor em Ciências da Religião (UMESP). Doutorando em Filosofia (USP). Professor no Departamento de Ciência da Religião da Universidade Federal de Juiz de Fora (UFJF).
} 
"O Tao que pode ser chamado de Tao / não é o verdadeiro Tao. $O$ nome que pode ser nomeado / não é o eterno nome" ${ }^{11}$. Estas palavras retiradas do Tao Te Ching apontam para o dilema que marca a relação entre experiência religiosa e linguagem. Nota-se certa incapacidade da linguagem em expressar de modo pleno o encontro com o divino. Ao se tentar dar vazão ao que acontece na relação divino-humana, as palavras parecem vazias e destituídas de sentido. Elas se revelam deficitárias diante da grandeza da experiência religiosa. Entre a expressão e o que é expresso emerge distância infinita, apontando para a diferença entre a experiência e as formas pelas quais é dita. Neste sentido, lembra-nos Paul Tillich, a expressão revela, mas, simultaneamente oculta ${ }^{2}$. Ela diz sobre a experiência religiosa, mas não diz a experiência enquanto tal. Há intransponível distância entre a nomeação e o nomeado.

Diante deste hiato entre experiência e expressão, tentou-se algumas soluções. Nesta direção, a teologia negativa aparece diante da impossibilidade de nomeação positiva da transcendência, compreendendo a experiência religiosa como passível de ser expressa a partir da negação. Se Deus é sempre mais do que as proposições positivas podem dizer e expressar sobre ele, a saída é afirmar o que ele não é. Para Agostinho, partidário da superioridade da teologia negativa, esta solução evita a confusão entre criador e criatura e, especialmente, a mistura entre os atributos divinos e as coisas que se dão à nossa experiência corpórea. ${ }^{3}$ A teologia negativa, além de dizer negativamente a experiência do sagrado, também emprega oxímoros, valendo-se de predicados opostos. No livro X das Confissões, há significativo exemplo do uso deste recurso lingüístico. Ao tentar descrever sua "experiência religiosa", expressa na pergunta "que amo eu, quando Vos amo?", Agostinho responde:

Não amo a formosura corporal, nem a glória temporal, nem a claridade da luz, tão amiga destes meus olhos, nem as doces melodias das canções de todo gênero, nem o suave cheiro das flores, dos perfumes ou dos aromas, nem o maná ou o mel, nem os membros tão flexíveis aos abraços da carne.

\footnotetext{
${ }^{1}$ Apud. CROATTO, S. As linguagens da experiência religiosa. São Paulo: Paulinas, 2001, p.83.

${ }^{2}$ TILLICH, P . "Art and Ultimate Reality". In: CAPPADONA-APOSTOLOS, Diana. Art, Creativity and the Sacred. New York: Continuum, 1990, pp.220 e 221.

${ }^{3}$ AGOSTINHO. On The Gospel of St. John. Trad. Arthur West Haddon. Coleção Nicene and post Nicene Fathers, Vol. VII. Editado por Philip Schaff. Michigan, WM. B. Eerdmans, 1970. XXIII, 9. "Se não conseguis compreender o que Deus é, compreendei ao menos o que ele não é: fareis grande progresso, se não pensardes Deus de maneira diversa do que ele é. Deus não é um corpo, não é a terra, não é o céu, não é a lua, ou sol, ou as estrelas nenhuma destas coisas corpóreas. Pois, se ele não é as coisas celestes, muito menos é as coisas terrestres! Colocai todos as coisas corpóreas fora de questão".
} 
Nada disto amo, quando amo o meu Deus. E, contudo, amo uma luz, uma voz, um perfume, um alimento e um abraço, quando amo o meu Deus ${ }^{4}$.

Por meio de afirmações opostas, Agostinho revela sua influência neoplatônica, partindo do mais corpóreo para o incorpóreo 5 . Há negação explícita do modo categorial de enunciação, deixando o leitor contemporâneo perplexo e afoito por apreender algum sentido por detrás destas palavras contraditórias.

Estas palavras são contraditórias não somente por dizer e, logo em seguida, desdizerem-se. Pode-se questionar se a teologia negativa, como modo de expressão da experiência religiosa, no limite, não acaba por trair sua intenção inicial. Ela quer enunciar o objeto da experiência como algo que está para além de todos os nomes. Entretanto, para dizer isso há de se nomear positivamente o objeto da experiência religiosa. Precisa-se, por exemplo, dizer que Deus está acima de todos os nomes. Ora, mas nesta formulação, já não se nomeia, ainda que de modo bastante indeterminado, aquilo que se considera inominável? É deste problema que surge a necessidade desta linguagem de se retomar continuamente para não terminar numa regressão lingüística infinita, uma vez que aquilo que se denomina pelo nome de "Deus" está sempre além desta designação e assim infinitamente. A designação desta transcendência como "abismo" (Abgrund) busca preservar a impossibilidade da linguagem em alcançar seu objeto, ainda que também se lhe conceda um nome. Este aspecto é expresso por Meister Eckhart: "Se por acaso a mosca fosse dotada de razão e pudesse racionalmente buscar o abismo eterno do ser divino, de onde viera, dizemos que Deus, à medida que é Deus, não poderia satisfazer a mosca. Portanto, roguemos a Deus para que nos livremos de Deus" ${ }^{\prime 6}$. Ora, o que significa orar a Deus para nos livrar de Deus? É possível compreender esta afirmação a partir da concepção de que há o Deus em si e Deus nas criaturas. Enquanto este se mostra ao intelecto humano, aquele é inacessível. Mas, para além desta abordagem mais tradicional, parece que nesta afirmação de Eckhart está posta a distância que separa a linguagem e o objeto da experiência religiosa. Do mesmo modo, coloca o problema da teologia negativa: ao negar, ela tem de nomear positivamente aquilo que seria inominável.

Este tema não se restringe somente à Idade Média, quando se observa o surgimento de importantes correntes místicas no âmbito do cristianismo,

\footnotetext{
${ }^{4}$ AgOstinHO. Confissões. Trad. J. Oliveira Santos e A. Ambrósio de Pina. Petrópolis, Vozes, 2002 (18a edição). X, 8

${ }^{5}$ Sobre este tema, GRIFFIN, Carl; PAULSEN, David. "Augustine and the Corporeality of God ". In : Harvard Theological Review, 95 (1), 2002, p.106.

${ }^{6}$ QUINT, J. KOCH, J. (ed). Meister Eckhart: Die Deutschen und Lateinischen Werke. Stuttgart e Berlin: Kohlhammer, 1936. 2:493.
} 
islamismo e judaísmo. A distância entre experiência e expressão aparece em autores contemporâneos. R. Otto, por exemplo, insiste que a experiência do numinoso, qualitativamente distinta de outros sentimentos, não é exprimível por meio da linguagem categorial, empregando com certa freqüência o termo inefável para se referir a ela. Entretanto, como é característico da experiência religiosa adquirir expressão, pode-se indicar o sentimento por meio de analogias, isto é, de modo indireto. Ainda que a experiência do numinoso seja de outra ordem, é possível empregar paralelos da experiência cotidiana para acenar o que se passa na experiência com este aspecto não-racional do sagrado. Em suas palavras, "O objeto permanece na indestrinçável escuridão da experiência não-conceitual, do puro sentir, não podendo ser interpretado, mas apenas insinuado pela partitura dos ideogramas interpretativos (...). Sendo 'totalmente outro', ele é totalmente indizível"7. É importante observar o estatuto pré-hermenêutico do sentir em relação ao totalmente outro. As analogias, expressas por meio de ideogramas, não dizem de modo preciso a experiência do numinoso, até mesmo porque esta é essencialmente não-racional. Como se pode observar, Otto retoma a antiga percepção da distância entre experiência e expressão numa obra que buscava evitar abordar o sagrado valendo-se de linguagem e conceitos inadequados. Deste modo, o sagrado em Otto é constituído por um aspecto racional, que se deixa expressar pela clareza da linguagem categorial e outro não-racional. É neste elemento que a experiência se afasta da linguagem.

Apesar das proximidades, é importante observar que há importante elemento que distancia os autores aqui citados. A diferença fundamental reside justamente no conceito de experiência religiosa. Grace Jantzen aponta que na modernidade, o conteúdo objetivo da experiência perde seu lugar central para a subjetividade. Especialmente a partir do idealismo póskantiano e o romantismo (notadamente com Schleiermacher), a ênfase no sentimento de dependência promove a privatização da religião ${ }^{8}$. Esta subjetivação da religião é reforçada por aqueles que buscam resistir à razão que parece tudo dominar, especialmente na redução kantiana da religião a adendo da moral. Distante, mas muito próximo de Kant, Friedrich

${ }^{7}$ OTTO, R. O sagrado. Trad. Walter O. Schlupp. Petrópolis/São Leopoldo, Vozes/Sinodal, 2007, p.98.

8 JANTZEN, Grace M. Becoming Divine. Towards a Feminist Philosophy of Religion. Bloomington e Indianapolis: Indiana University Press, 1999. "Eu já sugeri que não é sem significado que este tipo de apelo à experiência religiosa começa na filosofia da religião durante o século XIX, um tempo de triunfo do imperialismo e do capitalismo" (p.118). Esta privatização da religião no conceito emergente de experiência corresponderia no plano social à privatização das mulheres. Enquanto os homens se ocuparão dos negócios no âmbito público, caberia às mulheres de classes mais abastardas criar lares ideais, moldados pela moralidade burguesa. Este processo de subjetivação, tendo como foco principal a crítica a W. James é desenvolvido também em "Mysticism and Experience". In: Religious Studies, 25, 1989, p.295-315. 
Schleiermacher também tem de suprimir o saber "para encontrar lugar para a crença" ${ }^{\prime}$. A fé (Glaube) se restringe à subjetividade. Assim, diante do avanço da razão e da moral, situa-se aquilo que é puramente religioso no sentimento de dependência absoluta. Uma vez que, após Kant, não é mais possível o conhecimento do divino, Schleiermacher encontrara como saída a afirmação do sentimento imediato de dependência, que desperta uma certeza indemonstrável ${ }^{10}$. Em outras palavras, a filosofia da religião, já no seu berço por meio da subjetivação da categoria compreensiva "experiência religiosa", elege como seu objeto isso que se retira para a noite escura da alma, mas é determinante para a religião: o contato imediato com a divindade. Essa concepção ressoará com toda radicalidade em William James, que aponta para a experiência religiosa como característica originária da religião e para quem, "A religião é essencialmente privada e individualista; sempre excede nossos poderes de formulação" ${ }^{11}$.

Além de responder aos desafios da razão, a categoria experiência religiosa também se revela como alternativa ao pluralismo religioso. Uma vez que o cristianismo reconhece a pertinência de outras manifestações religiosas, não podendo sustentar sua exclusividade como em outros tempos, apontase para certo núcleo comum da religião ao qual, no final, todas as experiências contingenciais se remeteriam ${ }^{12}$. Em outros termos, ainda que as religiões se mostrem numa variedade de manifestações, a sua plenitude remeteria para a experiência com transcendente. No âmbito da ciência da religião, a categoria experiência religiosa se mostra como possibilidade de encontrar elemento que permeasse as várias manifestações do sagrado. $\mathrm{O}$ argumento era: se o termo religião era por demais ocidental ${ }^{13}$, o mesmo

\footnotetext{
${ }^{9}$ KANT, I. Crítica da razão pura. Trad. Manuela Pinto dos Santos e Alexandre Fradique Morujão. Lisboa, Calouste Gulbenkian, 2001, BXXX.

${ }^{10}$ SCHLEIERMACHER, Friedrich. The Christian Faith. Edinburgh: T. \& T. Clark, 1989. $\S 108$, p.481. Para Otto isso se evidencia pela compreensão da absoluta dependência como auto-consciência, o que significa dizer que estamos direcionados à interioridade do sujeito e não a um objeto. "O sentimento religioso seria então diretamente e em primeiro lugar uma autopercepção, ou seja, uma sensação sobre minha própria condição peculiar, qual seja, minha dependência. Somente por inferência, ao acrescentar em pensamento uma causa fora de mim, é que, segundo Schleiermacher, chegaríamos ao divino" (OTTO, R. $O$ sagrado. Trad. Walter O. Schlupp. Petrópolis/São Leopoldo: Vozes/Sinodal, 2007, p.42) 11 JAMES, William. As variedades da experiência religiosa. São Paulo: Cultrix, 1991, p.268.

${ }^{12}$ Cf. SHARF, R Robert. "Experience”. In: TAYLOR, Mark C. Critical Terms for Religious Studies. Chicago: The University of Chicago Press, 1998, p.94-107

${ }^{13}$ Como se sabe, o termo religião é de origem latina. Há duas possíveis origens etimológicas. A primeira remete a Cícero que, no De natura deorum, afirma que a origem do termo é relegere, isto é, reler, de modo que seu sentido se aproxima de escrupuloso, referindo-se àquele que cumpre os deveres de cultos aos deuses. Há também a versão de Agostinho e Lactâncio, que concebem a origem do termo em Religare, assumindo mais claramente certos contornos cristãos ao significar religar. Se o termo se torna corrente nos idiomas relacionados ao Latim, ele é desconhecido em outras línguas.
} 
não se pode dizer da experiência religiosa, encontrada por toda a parte. No entanto, não se atentava que a compreensão de experiência que pautava as abordagens remete ao contexto do romantismo do século XIX com sua noção própria de subjetividade. Em especial, compreendia-se experiência religiosa dentro dos limites da subjetividade do sujeito.

Não obstante esta diferença e outras diferenças entre os autores citados, há pressupostos epistemológicos comuns. A experiência religiosa ocorre de maneira imediata, sem a mediação da cultura, da tradição e, principalmente, da linguagem. Há contato direto do sujeito religioso com seu objeto que extrapola e é anterior a todas estas determinantes. É como se houvesse de um lado a experiência e, de outro, a expressão. É dessa cisão que nasce a sensação de que a linguagem é incapaz de dizer plenamente a experiência.

Entretanto, é curioso notar que muitos dos autores que tratam da experiência religiosa, buscando indicar seu núcleo inacessível e destacando a distância entre experiência e expressão, não tomam este mesmo pressuposto ao considerar o acesso ao seu objeto de estudo. Para tratar da experiência religiosa nos seus múltiplos aspectos, partem de relatos ou de textos escritos por indivíduos que passaram pela experiência religiosa. Deste modo, R. Otto, por exemplo, para tratar deste núcleo inacessível cita inúmeros textos que deixariam entrever aspectos do encontro com o numinoso ${ }^{14}$. No entanto, se há distância entre experiência e expressão, como se pode ter acesso à experiência religiosa em si mesma por meio dos textos que buscam descrevê-la? Se há hiato entre experiência e expressão, em que medida o recurso a textos que dão expressão à experiência podem ser tomados como exemplares da experiência religiosa inefável? Este procedimento não seria, no mínimo, questionável?

A concepção que marca a distância entre experiência e expressão também conduz à conclusão de que a experiência molda a tradição. Mais do que isso. Em geral se concebe que a experiência religiosa dá origem à tradição. Uma vez que a experiência é mais originária, anterior e tem mais ser (por ter contato imediato com o divino), ela é causa da tradição que, por ser indireta e mediata, acaba na dependência da experiência. A tradição (que envolve símbolos, mitos, ritos e dogmas) aparece como tentativa de explicação, mais ou menos racional, da experiência religiosa, compreendida como seu ato de fundação. Nesta perspectiva, situa-se novamente o clássico de W. James As variedades da experiência religiosa. Ele não adota o caminho de partir de um sistema metafísico a priori para a experiência religiosa;

\footnotetext{
${ }^{14}$ Por exemplo: na descrição do aspecto aterrorizante e misterioso do numinoso, Otto cita a seguinte passagem de Agostinho: "O que é aquilo que reluz através de mim e percute meu coração sem feri-lo? estremeço tanto quanto me inflamo. Estremeço no que lhe sou dessemelhante. Inflamo-me no quanto lhe sou semelhante" (OTTO, R. O sagrado. rad. Walter O. Schlupp. Petrópolis/São Leopoldo: Vozes/Sinodal, 2007, p.60).
} 
antes, constitui-se espécie de metafísica a posteriori, que se erige a partir e tomando como base a experiência da realidade. Para James, a experiência religiosa se mostra como mais fundamental e determinante para a religião do que os dogmas e as doutrinas. Em seus próprios termos, "Acredito que o sentimento é a fonte mais profunda da religião e que as fórmulas filosóficas e teológicas são produtos secundários, como as traduções de um texto para outra língua" 15 .

Por outro lado, mas no interior desta mesma perspectiva, a experiência religiosa também é compreendida como ruptura em relação às tradições religiosas estabelecidas. Os relatos sobre a vida de Buda, Jesus, Paulo, Maomé e tantos outros personagens religiosos destacam o acontecimento de uma experiência religiosa originária que fundamentaria sua ação posterior. Nesta experiência originária, do ponto de vista do religioso que passa por esta experiência, estaria não a afirmação de uma tradição, mas sua negação mediante certa experiência fundante de ruptura. Do ponto de vista do estudioso da religião, entretanto, estes personagens antes de passarem pela experiência fundante que os levaria à "ruptura" com seus sistemas de origem, partilharam das cosmologias oriundas de suas tradições, a ponto de tê-las como substrato, isto é, como referencial simbólico. Se for assim, a experiência talvez seja continuidade da tradição. Talvez, evento performático que necessita emergir periodicamente para "renovar" a tradição, mas não necessariamente repudiá-la. Neste sentido, compreende-se que a experiência religiosa determina ou nega fundamentalmente a tradição. Estes dois aspectos nada mais são do que duas faces da mesma moeda, que encontram seu pressuposto na distância que separa experiência religiosa e sua (im)possibilidade de expressão. Neste caso, a experiência possui autonomia em relação à tradição, sendo determinante em relação a ela, mas nunca se submetendo a ela.

Em suma, nota-se certo pressuposto epistemológico de distância entre experiência e religiosa e linguagem no tratamento deste tema. Diante do reconhecimento dos limites da expressão lingüística, apela-se à teologia negativa. Esta, no entanto, para não cair numa cadeia infinita de reminiscência acaba tendo que nomear o "inominável". Além disso, há o problema com relação ao modo de acesso à experiência em si mesma. Se há distância entre linguagem e experiência, como justificar que se fale da experiência religiosa por meio de textos que seriam expressões desta experiência? Por fim, como conseqüência do pressuposto básico, conclui-se que a experiência religiosa tem mais ser do que a tradição e, portanto, fundadora da tradição. Cabe ainda destacar que estas conseqüências são ainda mais acentuadas com a ênfase subjetivista da modernidade na compreensão da categoria "experiência religiosa".

\footnotetext{
${ }^{15}$ JAMES, William. As variedades da experiência religiosa. São Paulo: Cultrix, 1991, p.268.
} 
No entanto, em que medida é sustentável a pressuposição que separa linguagem e experiência religiosa? Não seria a linguagem componente essencial da experiência religiosa? Em primeiro lugar, cabe tematizar a linguagem como condição de possibilidade da experiência, de modo que não se pode compreendê-la como acontecimento à parte da linguagem. Ambas ocorrem conjuntamente, de modo que a experiência do sagrado, mesmo quando se autodenomina inefável, é mediada pela linguagem. Não há experiência pura e imediata. A experiência religiosa, inclusive a mais mística, inscreve-se num horizonte de compreensão de modo que não se estende para além da linguagem, o que implicaria na sua ininteligibilidade. Poder-se-ia questionar: Mas, ora, não é justamente isso que alegam os místicos? Não seria sua experiência questionamento da racionalidade que a tudo quer dominar? Não estaria no seu caráter extra-ordinário justamente apontar os limites da razão? Queremos indicar que a experiência religiosa não extrapola estes limites, pois podemos falar sobre ela. Aliás, os místicos são pródigos no muito dizer sobre suas experiências.

A hermenêutica filosófica pode nos auxiliar na compreensão desta cumplicidade entre experiência e linguagem. Neste sentido, é importante superar aquilo que Heidegger denomina de compreensão instrumental da linguagem, tida como mero meio de comunicação ${ }^{16}$. Aliás, este é um dos pressupostos das concepções que tratam de apontar para o hiato entre experiência e expressão. Do ponto de vista da consideração da linguagem como instrumento, pode-se, ao menos, indicar três tendências, sendo que a primeira se revela mais amplamente utilizada para a compreensão da experiência religiosa. Do ponto de vista fenomenológico, a linguagem seria instrumento para dar expressão a intecionalidades pré-lingüísticas da consciência ${ }^{17}$. Esta perspectiva aparece no pensamento de Otto. Para ele, o irracional seria inalcançável pela linguagem conceitual. $\mathrm{O}$ único meio de expressão possível deste âmbito pré-lingüístico se dá por meio de ideogramas, isto é, de modo indireto. A partir do $\$ 59$ de Faculdade do Juízo de Kant

\footnotetext{
${ }^{16}$ Cf. HEIDEGGER, M. A essência da verdade. Edição Bilíngüe. Trad. Carlos Morujão. Porto: Porto Editora, 1995, p.15. Heidegger também afirma: "Pois as palavras e a linguagem não constituem cápsulas, em que as coisas se empacotam para o comércio de quem fala e escreve". (HEIDEGGER, M. Introdução à metafísica. Trad. Emmanuel Carneiro Leão. Rio de Janeiro: Tempo Brasileiro, 1999, p.44).

${ }^{17}$ Este tipo de pressuposição guia, por exemplo, a abordagem de Csordas. Logo na introdução de seu texto, A corporeidade como um paradigma para a antropologia, afirma: "Essa abordagem da corporeidade parte da premissa metodológica de que o corpo não é um objeto a ser estudado em relação à cultura; mas é o sujeito da cultura; em outras palavras, a base existencial da cultura" (CSORDAS, Thomas. A corporeidade como um paradigma para a antropologia. In: Corpo/significado/cura. Porto Alegre: UFRGS, 2008, p.102; cf. também p.126-134.
} 
e de outros pensadores do século XIX (Como J. Fries e Wilhelm DeWette), Otto retoma o esquematismo simbólico, capaz de nos fornecer apenas referência indireta. ${ }^{18}$ Além desta primeira tendência, bastante importante para a abordagem da experiência religiosa, há, em segundo lugar, abordagem pragmática, segundo a qual a linguagem pode ser remetida a um ato. E por fim, a teoria do conhecimento, que concebe a linguagem como tendo por função oferecer representação, a mais fiel possível, do mundo. Neste caso, a efetividade (Wirklichkeit) é tida como todo independente da linguagem e, em última instância, da representação e da consciência.

Entretanto, a linguagem não apenas designa os entes, mas constitui a experiência e a compreensão de mundo. Para haver encontro entre o ser humano e os entes é necessário que se instaure uma abertura onde este encontro entre sujeito e objeto se torna possível. Deste modo, a experiência pressupõe esta clareira (Lichtung) onde este encontro se efetua, de modo que o sagrado e aquele que o experimenta compartilham de um mundo. Com isso, Heidegger busca apontar certo limite da compreensão da linguagem encontrada nas filosofias da consciência, que se prendem à análise lógica da das proposições, não abordando a articulação entre ser-no-mundo e significação. Em Ser e tempo, afirma Heidegger que "para se fazer a experiência 'fatual' de um ente é preciso já se ter compreendido o ser, não obstante sem conceituá-lo" ${ }^{19}$.

\footnotetext{
${ }^{18}$ Neste sentido, conferir o $\$ 59$ da Crítica da faculdade do juízo de Kant. Neste momento do texto, Kant busca demonstrar como o belo pode ser tomado como símbolo de eticidade, como se o interesse por ele pudesse indicar algum tipo de disposição moral. Devido à tarefa à qual se propõe, Kant distingue dois modos de representação (Darstellung): o esquemático e o simbólico. Seu objetivo é criticar aqueles que defendem certa incompatibilidade entre intuição e símbolo. Neste sentido, diz Kant: “(...) pois, o modo de representação simbólico é somente uma espécie do modo de representação intuitivo. Ou seja, este (o intuitivo) pode ser dividido em modo de representação esquemático e em modo de representação simbólico". Ainda afirma: "todas as intuições que submetemos a conceitos a priori são ou esquemas ou símbolos, dos quais os primeiros contêm apresentações diretas, e os segundos apresentações indiretas do conceito" (KANT, I. Crítica da Faculdade do Juízo, p. 255-256 (§59)). Por essas citações, fica evidente que tanto o símbolo como o esquematismo são modos de apresentação. No entanto, em que consiste a especificidade de cada um? No simbolismo, com seu interesse pelo belo, a apresentação se faz de modo indireto. Já no esquematismo, a representação se dá de maneira direta. Isso significa dizer que no segundo caso há perfeita conformação entre conceito e intuição, ao passo que no segundo caso a referência ocorre apenas indiretamente. Um exemplo pode auxiliar na compreensão do simbolismo. Não referimos cor somente a algum conceito do entendimento que se aplicaria de maneira direta a ela. É possível que se aplique a outro objeto da intuição por analogia. Nessa operação, a imaginação age. Entretanto, já não está submetida ao limite que sofria no esquematismo podendo refletir a forma de modo livre, dando origem a ideias.

${ }^{19}$ HEIDEGGER, M. Ser e tempo. Trad. Márcia de Sá Cavalcante. Petrópolis: Vozes, 1999, $\S 63$, Vol. II, p.108.
} 
Heidegger identifica três momentos desta estrutura, que podem apenas ser abordados distintamente para fins didáticos, visto que se articulam na composição da estrutura prévia da compreensão. Neste sentido, é importante a seguinte passagem: "Sentido é a perspectiva em função da qual se estrutura o projeto pela posição prévia [Vorhabe], visão prévia [Vorsicht] e concepção prévia [Vorgriff]. É a partir dela que algo se torna compreensível como algo" ${ }^{20}$. Com isso, nota-se como Heidegger não se refere a algo que seria pré-linguístico. Em Heidegger, pré-predicativo não é sinônimo de pré-lingüístico. O mundo é pré-predicativo, uma vez que é ele quem fornece a moldura a partir de onde toda predicação é possível. Se ele é condição de possibilidade para a predicação, ele mesmo não pode ser predicável.

Esta compreensão de linguagem afeta diretamente o cerne do conceito tradicional de experiência religiosa: contato imediato entre sujeito e objeto. O acesso ao sagrado é mediado por um mundo de significações. Ele se dá sempre num como, num modo de doação determinado pelo horizonte que se revela como condição de possibilidade para o acontecer da experiência religiosa. $\mathrm{O}$ acesso aos entes já pressupõe o desvelamento de um mundo, de modo que o acesso aos entes se dá na base de uma compreensão de ser que é anterior à própria experiência. Em outros termos, antes de cada objeto particular há o mundo, de forma que o acesso aos entes é medido pela significação. Assim, a experiência é interpretação que pressupõe um mundo compartilhado de significações.

Desta forma, toda a experiência, segundo Heidegger, é determinada por concepções prévias, uma vez que "A interpretação de algo como algo se funda, essencialmente, numa posição prévia, visão prévia e concepção prévia. A interpretação nunca é apreensão de um dado preliminar, isenta de pressuposições" ${ }^{21}$. A pré-compreensão é a base para a interpretação e condição de possibilidade para a própria experiência, de modo que não há lugar fora da temporalidade onde ela acontece ou mesmo a partir de onde poderia ser analisada. A experiência se insere numa organização da totalidade dos entes. No seu pensamento mais tardio, Heidegger identifica esta estrutura prévia com a linguagem. A linguagem faz com que os entes apareçam de determinado modo, sendo aquilo que doa, mas que nunca se dá a si próprio. Com isso, torna-se impossível qualquer tratamento objetivante da linguagem. Esta impossibilidade de experiência destituída de juízos prévios é reconhecida na afirmação de que "Falamos a partir de uma linguagem"22. Já estamos imersos numa rede de significações, herda-

\footnotetext{
${ }^{20}$ HEIDEGGER, M. Ser e tempo. Trad. Márcia de Sá Cavalcante. Petrópolis: Vozes, 1999, $\S 32$, Vol I, p.208.

${ }^{21}$ HEIDEGGER, M. Ser e tempo. Trad. Márcia de Sá Cavalcante. Petrópolis: Vozes, 1999, $\S 32$, Vol. I, p.207.

${ }^{22}$ HEIDEGGER, M. "O caminho para a linguagem”. In: HEIDEGGER, M. A caminho da linguagem. Petrópolis: Vozes, 2003, p.203.
} 
das de mensagens enviadas pelo passado, que determina toda nossa experiência, inclusive a experiência religiosa. É curioso observar como forças antagônicas confluem neste ponto: tanto o ideal da razão absoluta da Aufklärung como a experiência religiosa imediata buscam justamente o contato com uma presença indefectível, revelando sua motivação metafísica $^{23}$. Com a hermenêutica, a questão passa a ser não mais como é possível uma experiência religiosa destituída de conceitos prévios, mas como eles participam na constituição da experiência enquanto tal.

Heidegger, especialmente após a década de 30, esforça-se em demonstrar que a linguagem se configura como mediadora que condiciona nossas perspectivas, nossa experiência do mundo, das coisas, em suma, dos entes. Ela é aquilo que chamamos anteriormente de compreensão prévia, instaurando esta abertura onde sujeito e objeto se encontram. A linguagem abre o horizonte a partir do qual toda experiência é possível. Se a linguagem é a casa do ser $^{24}$, ela é também nossa morada, pois como seres-no-mundo nossa compreensão do mundo é situada lingüisticamente e mediada por uma tradição. É pela linguagem que o mundo se abre para nós e que as coisas adquirem ser. Como afirma Heidegger, "devemos, portanto, frisar bem: nenhuma coisa é, onde a palavra, isto é, o nome falhar. É a palavra que concede ser às coisas" 25 .

Nesta esteira, H. G. Gadamer afirma que o "ser que pode ser compreendido é a linguagem" ${ }^{26}$. A verdade do ser não acontece nem antes, nem depois, nem por detrás ou na frente da linguagem. Ela acontece na linguagem. Assim, estar no ser é pertencer a uma linguagem que, por sua vez, se constitui historicamente (tradição), determinando o horizonte de abertura onde toda a experiência de mundo é possível. Deste modo, há a mediação da linguagem de toda forma de experiência, revelando-a como o lugar da manifestação do ser. Em outros termos, a linguagem constituída historicamente é a condição de possibilidade da experiência. Somente há experiên-

\footnotetext{
${ }^{23}$ Neste sentido, é importante lembrar-se de Derrida quando afirma: "Quanto ao conceito de experiência, ele é aqui bastante embaraçoso. Como todas as noções de que aqui nos serviremos, ele pertence à história da metafísica e nós só podemos utilizá-lo sob rasura. "Experiência" sempre designou a relação a uma presença, tenha ou não esta relação a forma da consciência. Devemos, todavia, de acordo com esta espécie de contorção e de contenção à qual o discurso é aqui obrigado esgotar os recursos do conceito experiência antes e com o fim de alcançá-la, por desconstrução, em sua última profundeza. É a única condição para escapar ao mesmo tempo ao 'empirismo' e às críticas 'ingênuas' da experiência” (DERRIDA, Jacques. Gramatologia. São Paulo: Perspectiva/EDUSP, 1973, p.74). ${ }^{24}$ HEIDEGGER, M. A essência da linguagem. In: In: HEIDEGGER, M. A caminho da linguagem. Petrópolis: Vozes, 2003, p.127.

${ }^{25}$ HEIDEGGER, M. A essência da linguagem. In: In: HEIDEGGER, M. A caminho da linguagem. Petrópolis: Vozes, 2003, p.126.

${ }^{26}$ GADAMER, HG. Verdade e método. Petropólis: Vozes, 1999, p.687. "Sein, das verstanden werden kann, ist Sprache".
} 
cia religiosa, porque habitamos um mundo de significações. A experiência religiosa não ocorre para além dos limites deste mundo, visto que somos seres finitos. Enquanto tal, não podemos abandonar esta finitude que nos inscreve num horizonte de compreensão.

Poder-se-ia acusar, como Habermas o faz ${ }^{27}$, essa compreensão da experiência de tradicionalismo. No entanto, reconhecer o pertencimento a uma tradição, não significa completa submissão a-crítica aos conceitos prévios herdados, como se a experiência religiosa fosse apenas a repetição do que está estabelecido. É daqui que surge a noção de que a experiência religiosa é ruptura com uma tradição anterior. Mas, como já observado, esta ruptura nunca consegue ser total. Sempre se carrega muito daquilo de que se quer livrar. G. Vattimo endossa esta posição ao destacar que o pertencimento à determinada tradição não significa submissão passiva aos pré-conceitos herdados, "já que o ser lançado numa abertura histórica é sempre, indivisivelmente, um participar ativo em sua constituição, interpretação criativa, transformação ${ }^{\prime 2}$. Pontuar a superioridade e anterioridade da tradição em relação à experiência religiosa não significa aceitação resignada daquilo que se herda. Não é integrar-se de forma harmoniosa na tradição. Por outro lado, também não é relação imediata com o divino, rompendose abrupta e completamente com a tradição. Antes, parte-se de um fundamento hermeneuticamente construído e, enquanto tal, não se mostra normativo. Jacques Derrida expressou isso ao afirmar: "Meu desejo se parece com aquele de um apaixonado pela tradição que gostaria de se livrar do conservadorismo". ${ }^{29}$ Deste modo, a experiência, a partir do interior mesmo de uma tradição, a coloca em questão. O reconhecimento da finitude humana, e sua conseqüente inserção num horizonte constituído historicamente, não permite que se afirme pensamento crítico como mero abandono da tradição. O pensamento crítico é exercido em relação a ela, que afinal é a única coisa da qual dispomos.

\footnotetext{
${ }^{27}$ Se toda a experiência de mundo possível é dada pela tradição (linguagem, herança), há a recuperação da importância do lugar da tradição. Ao entroná-la, traz-se novamente à tona seu dogmatismo e autoritarismo. Na leitura de Habermas, Gadamer enfatiza a continuação da tradição e não tanto as rupturas. Segundo Habermas, "A substancialidade do que é historicamente pré-dado não permanece sem ser afetado quando é submetido à reflexão (...). O pré-juízo de Gadamer pelo direito dos pré-juízos certificados pela tradição nega o poder da reflexão" (HABERMAS, J. A Review of Gadamer's Truth and Method. In: DALLMAYR, T; McCARTHY, T. (editores). Understanding and Society Enquiry. Indiana: University of Notre Dame Press, 1977, p.358.)

28 VATTIMO, G. Para além da interpretação. $O$ significado da hermenêutica para a filosofia. Rio de Janeiro: Tempo Brasileiro, 1999, p.122.

${ }^{29}$ DERRIDA, Jacques; ROUDINESCO, Elisabeth. De que amanhã... Trad. André Telles. Rio de Janeiro: Jorge Zahar, 2004, p.13.
} 
No entanto, esta interpretação da experiência religiosa a partir da tradição, especialmente quando se pensa no caso do misticismo, conseguiria compreender satisfatoriamente a percepção da cisão entre experiência e expressão vivida pelo religioso? Se a experiência se dá a partir de uma tradição, como explicar o lugar onde a palavra falha? Não seria este sinal de que a experiência está alçando vôos para além dos limites circunscritos da linguagem? Neste sentido, penso que as críticas de Steven Katz, e seu paradigma da filosofia de Wittgenstein encontram seus limites ${ }^{30}$. Segundo ele, a experiência religiosa, por mais profunda e inefável que pareça, não poderia exceder a linguagem sob o risco de se tornar ininteligível e incomunicável. Ora, mas não é justamente isso que alegam os míticos? Eles justamente não afirmam que o encontro divino-humano é inexprimível e indizível?

Neste sentido, a abordagem heideggeriana da linguagem, justamente por se abrir para o mistério, parece contribuir para articulação entre experiência religiosa (neste caso, mística) e linguagem. Em alguns casos, a experiência religiosa leva a linguagem ao limite. Conduzir a linguagem ao seu limite, entretanto, não significa afirmar experiência não-verbal, mas antes, busca-se ir às fronteiras do sentido, até onde as palavras são desterritorializadas. Mas, nunca se ultrapassa essas fronteiras. Assim, há aqui uso criativo da linguagem, denominado por Heidegger de poesia (Dichtung). Neste sentido, aquele que tem a experiência religiosa, muita vez, vale-se de termos do cotidiano para falar sobre sua experiência. Entretanto, estes termos são destituídos de seu caráter descritivo e não podem mais ser tomados literalmente, uma vez que assumem conotação simbólica. Esta re-semantização traz consigo certo caráter de desfundamentação, uma vez que é preciso estranhamento em relação ao horizonte de compreensão já aberto. Mas este estranhamento se dá a partir de dentro do próprio horizonte, não se colocando fora dele. Vai até seu limite, mas não o excede. Neste sentido, aparece o aspecto aparentemente inexprimível da experiência religiosa. Ainda que não trate especificamente deste tema, Heidegger nos auxilia na sua compreensão ao abordar o dito poético: "Mas como a linguagem como linguagem vem à palavra? Raramente, lá onde não encontramos a palavra certa para dizer o que nos concerne, o que nos provoca, oprime ou entusiasma (...) Quando se trata de algo que nunca foi dito, tudo fica na dependência de a linguagem conceder ou recusar a palavra apropriada" 31 . Este momento apontado por Heidegger é aquele em que se é conduzido aos limites da linguagem, em direção ao que se põe

\footnotetext{
${ }^{30}$ KATZ, Steven. "Language, Epistemology, and Mysticism". In: KATZ, S. (editor). Mysticism and Philosophical analysis. New York: Oxford University Press, 1978, p.25.

${ }^{31}$ HEIDEGGER, M. "A essência da linguagem". In: HEIDEGGER, M. A caminho da linguagem. Petrópolis: Vozes, 2003, p.123.
} 
além do horizonte já aberto, para aquilo que permanece velado e, portanto, mistério. Talvez, por esta razão, se fale tanto em revelação quando o assunto é experiência mística.

\section{Conclusão}

Assim, partiu-se do problema da inadequação entre experiência e expressão a fim de mostrar como, no fundo, a questão da relação entre experiência religiosa e linguagem se coloca de modo mais fundamental do ponto de vista da hermenêutica, quando se passa a reconhecer o papel da linguagem (e com ela, da tradição) na constituição da experiência. Assim, a linguagem não ocorre como momento posterior, quando se trata de dar expressão à experiência, mas é condição de possibilidade e parte da experiência. Entretanto, há de se reconhecer que na experiência religiosa, especialmente a mística, há outro tipo de relação com a linguagem, levando-a ao seu limite. Em relação a este aspecto, a concepção heideggeriana de linguagem parece mais promissora do que a abordagem de Wittgenstein. Reconhece-se, como no prólogo do Evangelho de João, que o logos não apenas descreve, mas também revela, uma vez que nomear não é apenas expressar, mas trazer à palavra, trazer ao ser. A linguagem desvela os entes, cria o mundo. Por criar o mundo é ela que faz com que o ser humano tenha uma história e seja histórico. "Unicamente onde há palavra, haverá mundo (...) A palavra é um acontecimento histórico: aquele que dispõe a suprema possibilidade de que o homem seja" ${ }^{32}$. Assim, antes da subjetividade pura e da experiência imediata, há a linguagem.

\section{Referências bibliográficas}

AgOSTINHO. Confissões. Trad. J. Oliveira Santos e A. Ambrósio de Pina. Petrópolis: Vozes, 2002.

On The Gospel of St. John. Trad. Arthur West Haddon. Coleção Nicene and post Nicene Fathers, Vol. VII. Editado por Philip Schaff. Michigan, WM. B. Eerdmans, 1970.

${ }^{32}$ HEIDEGGER, M. “A linguagem”. In: HEIDEGGER, M. A caminho da linguagem. Petrópolis: Vozes, 2003, p.25. 
CROATTO, S. As linguagens da experiência religiosa. São Paulo: Paulinas, 2001.

CSORDAS, Thomas. Corpo/significado/cura. Porto Alegre: UFRGS, 2008.

DERRIDA, Jacques. Gramatologia. São Paulo: Perspectiva/EDUSP, 1973.

DERRIDA, Jacques; ROUDINESCO, Elisabeth. De que amanhã... Trad. André Telles. Rio de Janeiro: Jorge Zahar, 2004.

GADAMER, H-G. Verdade e método. Petrópolis: Vozes, 1999.

GRIFFIN, Carl; PAULSEN, David. "Augustine and the Corporeality of God ". In : Harvard Theological Review, 95 (1), 2002, p.97-118.

HABERMAS, J. A Review of Gadamer's Truth and Method. In: DALLMAYR, T. McCARTHY, T. (editores.). Understanding and Society Enquiry. Indiana: University of Notre Dame Press, 1977, p.335-363.

HEIDEGGER, M. "O caminho para a linguagem". In: HEIDEGGER, M. A caminho da linguagem. Petrópolis: Vozes, 2003.

1995.

A essência da verdade. Trad. Carlos Morujão. Porto: Porto Editora, Introdução à metafísica. Trad. Emmanuel Carneiro Leão. Rio de Janeiro: Tempo Brasileiro, 1999.

Ser e tempo. Trad. Márcia de Sá Cavalcante. Petrópolis: Vozes, 1999.

"O caminho para a linguagem". In: HEIDEGGER, M. A caminho da linguagem. Petrópolis: Vozes, 2003.

JAMES, William. As variedades da experiência religiosa. São Paulo: Cultrix, 1991.

JANTZEN, Grace M. Becoming Divine. Towards a Feminist Philosophy of Religion. Bloomington e Indianapolis: Indiana University Press, 1999.

315.

"Mysticism and Experience". In: Religious Studies, 25, 1989, p.295-

KANT, I. Crítica da razão pura. Trad. Manuela Pinto dos Santos e Alexandre Fradique Morujão. Lisboa: Calouste Gulbenkian, 2001.

Crítica da faculdade do juízo. Trad. Valério Rohden e António Marques. 2a edição. São Paulo: Forense Universitária, 2005.

KATZ, Steven. "Language, Epistemology, and Mysticism". In: KATZ, S. (ed). Mysticism and Philosophical analysis. New York: Oxford University Press, 1978.

OTTO, R. O sagrado. Trad. Walter O. Schlupp. Petrópolis/São Leopoldo: Vozes/ Sinodal, 2007.

QUINT, J. KOCH, J. (ed). Meister Eckhart: Die Deutschen und Lateinischen Werke. Stuttgart e Berlin: Kohlhammer, 1936. 
SHARF, R Robert. "Experience". TAYLOR, Mark C. Critical Terms for Religious Studies. Chicago: The University of Chicago Press, 1998, p.94-107

SCHLEIERMACHER, Friedrich. The Christian Faith. Edinburgh: T. \& T. Clark, 1989.

TILLICH, P . "Art and Ultimate Reality". In: CAPPADONA-APOSTOLOS, Diana. Art, Creativity and the Sacred. New York: Continuum, 1990.

VATTIMO, G. Para além da interpretação. O significado da hermenêutica para a filosofia. Rio de Janeiro: Tempo Brasileiro, 1999.

Endereço do Autor:

Programa de Pós-Graduação em Ciências da Religião Instituto de Ciências Humanas

Universidade Federal de Juiz de Fora

Campus Universitário

Rua José Lourenço Kelmer S/N

36036-000 Juiz de Fora - MG

e-mail: frederico.pieper@ufjf.edu.br 